\title{
PERBANDINGAN NILAI OVERALL EQUIPMENT EFFECTIVENESS (OEE) MESIN PACKER LAMA DAN MESIN PACKER BARU PADA PACKING PLANT INDARUNG (PPI) PT. SEMEN PADANG
}

\author{
Abd Latif, ${ }^{1}$ Riko Ervil, ${ }^{2}$ \\ ${ }^{1}$ Program Studi Teknik Industri Sekolah Tinggi Teknologi Industri (STTIND) Padang \\ email: ir.abd.latif@gmail.com, rikopdg@yahoo.com
}

\begin{abstract}
Packing Plant Indarung PT. Semen Padang which located at Jl. Raya Indarung - Padang has an important role to packing the cements. There are two types packer machines on Packing Plant Indarung, it is old packer machine and new packer machine. The objective of this study was to determine the effectiveness comparative of both packer machine types. One of method to measuring effectiveness machine is Overall Equipment Effectiveness (OEE). OEE is composed of three factors, that is Availability, Performance, and Quality. OEE score obtained by multiplying these factors. Result of the research show that Overall Equipment Effectiveness value of the new packer machines is higher than old packer machines. OEE score of the new packer machines is 69,14\%. While OEE score of the old packer machines is 76,80\%. Therefore, it was concluded that the effectiveness of new packer machine is better than old packer machine.
\end{abstract}

\section{Key Word : OEE, Packing Plant Indarung, Packer Machine, PT. Semen Padang}

\section{PENDAHULUAN}

Kemajuan teknologi yang semakin berkembang pesat seperti pada saat sekarang ini banyak perusahaan mulai mencari alternatif untuk meningkatkan revenue perusahaan, yaitu dengan menambah kapasitas produksi, efisiensi terhadap kegiatan logistik, dan meningkatkan pelayanan kepada konsumen, adapun salah satu cara yang dilakukan adalah melakukan perbaikan secara berkelanjutan (continous improvement) terhadap setiap proses yang dilakukan oleh pihak perusahaan.

PT. Semen Padang dalam hal melaksanakan produksi yang efektif dan efisien selalu berusaha untuk mengoptimalkan kegiatan produksinya. Salah satu upaya yang dilakukan oleh PT. Semen Padang yaitu dengan menambah dua buah mesin packer pada Packing Plant Indarung (PPI).

Packing Plant Indarung Sebelumnya hanya memiliki enam buah mesin packer jenis lama). Dimana mesin packer lama tersebut dalam cara kerjanya yaitu kantong semen masih dipasang secara manual ke mesin packer oleh pekerja. Oleh karena itu mesin packer lama ini minim terjadi kantong pecah yang dikategorikan sebagai product defect.
Dan sekarang PT.Semen Padang sudah menambah dua buah mesin packer baru untuk membantu proses pengantongan semennya. Mesin packer yang baru ditambahkan tersebut adalah mesin packer otomatis Ventomatic dimana pada mesin ini dilengkapi dengan alat penghantar kantong semen. Sehingga kantong semen dapat dipasang secara otomatis ke mesin packer.

Ditambahkannya dua mesin packer baru tersebut diharapkan dapat membantu kegiatan produksi pada Packing Plant Indarung di PT. Semen Padang. Akan tetapi pada prakteknya dua packer baru tersebut juga mempunyai kelemahan. Kelemahan tersebut berupa adanya kemungkinan macetnya mesin yang menghantarkan kantong semen menuju mesin packer sehingga menyebabkan aktifitas mesin terhenti selama proses maintenance dilakukan. Pada tabel berikut akan ditampilkan data kinerja dari masing-masing packer pada bulan Januari 2015 :

Sedangkan untuk persentase kantong pecah yang dialami masing-masing mesin packer dapat dilihat pada tabel berikut : 
Tabel 1. Kinerja Packer Bulan Januari 2015

\begin{tabular}{|c|c|c|c|c|c|c|c|c|c|c|c|}
\hline \multirow{2}{*}{ PACKER } & \multicolumn{5}{|c|}{ KINERJA PRODUKSI } & \multicolumn{6}{|c|}{ GANGGEAN INTERSAL } \\
\hline & $\begin{array}{l}\text { Kapanitas } \\
\text { detiga } \\
\text { (Tos) }\end{array}$ & $\begin{array}{l}\text { neveava } \\
\text { (ToN) }\end{array}$ & $\begin{array}{l}\text { Reatiaad } \\
\text { (TON) }\end{array}$ & 4 & 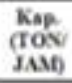 & $\begin{array}{c}\text { reosess } \\
\text { (1AD) }\end{array}$ & 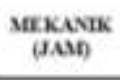 & $\underset{\text { (INST) }}{\text { LEsT/PWR }}$ & Mac & Jumlak & * \\
\hline $\begin{array}{c}\text { cacrevan } \\
\text { III }\end{array}$ & 74 & 27 & 21,41100 & 1699 & 1210 & 178 & 93 & 58 & 00 & 2413 & 31 \\
\hline IV & 24 & 27 & 22.96400 & 15,07 & 1105 & 260 & 332 & 33 & 124 & 9430 & 127 \\
\hline $\mathrm{v}$ & 74 & 27 & 30,47115 & 11314 & tsath & 20 & 27 & 33 & 00 & 198 & 11 \\
\hline vt & 74 & 32 & 26.932s & 412 & tist & 13 & 111 & 37 & 140 & 2013 & 40 \\
\hline $\mathrm{vm}$ & 74 & 32 & 3120800 & 9757 & ton 10 & 21 & 201 & 13 & 00 & $23 A^{7}$ & 12 \\
\hline $\mathrm{vm}$ & $\imath_{4}$ & 26.244 & nus 50 & 79.36 & $m 20$ & 278 & 57 & 65 & 120 & Het & 69 \\
\hline \multicolumn{5}{|c|}{ Rats rate Frodubai } & 3.19 & \multicolumn{5}{|c|}{ Rate-rats Gangtann } & s.2. \\
\hline $\begin{array}{c}\text { recriment } \\
\mathrm{IX}\end{array}$ & 74 & 12.5 & 19,20800 & 6706 & 9921 & 17 & 23 & 32 & 10 & 1532 & 2.4 \\
\hline$x$ & 74 & 32,3 & 24.43930 & 46.54 & 46.01 & 16 & 171 & 794 & 10 & 10635 & 144 \\
\hline \multicolumn{5}{|c|}{ Nats cats Frodtubat } & 23.96 & \multicolumn{5}{|c|}{ Rasorata Ciangauan } & 3.25 \\
\hline
\end{tabular}

Sumber : Laporan Kinerja Operasional Packer Pengantongan Indarung Bulan Januari 2015 PT. Semen Padang.

Tabel. 2 Persentase Kantong Pecah

\begin{tabular}{|c|c|c|c|}
\hline PACKER & $\begin{array}{c}\text { Target } \\
\text { Kantong } \\
\text { Pecah (\%) }\end{array}$ & $\begin{array}{c}\text { Realisasi } \\
\text { Kantong } \\
\text { Peeah (\%) }\end{array}$ & $\begin{array}{c}\text { Rata-rata } \\
(\%)\end{array}$ \\
\hline $\begin{array}{l}\text { Secterivis } \\
\text { III }\end{array}$ & 0.35 & 0.24 & \multirow{6}{*}{0,1996} \\
\hline rV & 0,35 & 0,16 & \\
\hline V & 0,35 & 0,14 & \\
\hline VI & 0,35 & 0,28 & \\
\hline Vu & 0,35 & 0,16 & \\
\hline VIII & 0,35 & 0,18 & \\
\hline $\begin{array}{l}\text { Eascker niand } \\
\text { IX }\end{array}$ & 0.35 & 0.24 & \multirow{2}{*}{0,2946} \\
\hline $\mathbf{x}$ & 0,35 & 0,34 & \\
\hline
\end{tabular}

Sumber: Laporan Performance Packer 3-10 Bulan Januari 2015 PT. Semen Padang.

Berdasarkan latar belakang diatas maka perlu dan diharapkan dapat menyelesaikan permasalahan yang ada, penulis merumuskan penelitian dengan judul "Perbandingan Nilai Overall Equipment Effectiveness (OEE) Antara Mesin Packer Lama dan Mesin Packer Baru Pada Packing Plant Indarung (PPI) PT. Semen Padang"

\section{METODE PENELITIAN}

Penelitian ini termasuk kedalam jenis penelitian komperatif, yaitu sejenis penelitian deskriptif yang ingin mencari jawaban secara mendasar tentang sebab-akibat, dengan menganalisis faktor-faktor penyebab terjadinya ataupun munculnya suatu fenomena tertentu pada masa sekarang.

Metoda penelitian komperatif bersifat $e x$ post facto, yaitu data dikumpulkan setelah semua kejadian yang dirangkum telah selesai berlangsung. Peneliti dapat melihat sebabakibat dari suatu fenomena dan menguji hubungan sebab-akibatnya dari data-data yang tersedia. (Nazir,2009).

Penelitian dilaksanakan pada Packing Plant Indarung (PPI) di PT. Semen Padang yang berlokasi di Jl. Raya Indarung, Padang 25237. Sedangkan waktu penelitian akan dilaksanakan pada bulan Juni sampai dengan Juli 2015.

Pada pengumpulan data dalam penelitian perbandingan nilai Overall Equipment Effectiveness (OEE) dibutuhkan data primer dan data sekunder. Data primer adalah data yang diambil secara langsung yaitu berupa wawancara dengan operator yang bertugas dan pengamatan langsung dilapangan. Data primer yang diambil untuk pengolahan data pada Penelitian ini adalah Ideal Run Time. 
Sedangkan data sekunder adalah data yang dapatkan dari perusahaan tempat penulis melakukan penelitian. Data sekunder yang diambil untuk pengolahan data dalam penelitian ini adalah waktu operasional, waktu setup, downtime, output, dan reject pada bulan Januari 2015.

Adapun yang akan dilakukan dalam pengolahan data ini yaitu melakukan perhitungan nilai OEE untuk kedua jenis mesin packer. Pada perhitungan nilai OEE tergantung pada tiga rasio utama yaitu :

1) Availability

2) Performance

3) Quality

\section{HASIL PENELITIAN DAN} PEMBAHASAN

\subsection{Pengolahan Data}

\subsubsection{Availability}

Perhitungan yang dilakukan untuk mendapatkan nilai Availability adalah dengan rumus :

$$
\begin{gathered}
\text { Availability }=\frac{\text { operating Time }}{\text { Loading Time }} \times 100 \% \\
\text { Operating time }=\begin{array}{c}
\text { loading time }- \text { unplanned } \\
\text { downtime }
\end{array}
\end{gathered}
$$

Berdasarkan rumus diatas maka diperoleh nilai Availability pada masing-masing mesin packer lama serta rata-rata persentase Availability mesin packer lama pada tabel

\begin{tabular}{|c|c|c|c|c|}
\hline \multirow[t]{2}{*}{ Mrent } & $\begin{array}{c}\text { Lauding Rume } \\
\text { (janj) }\end{array}$ & $\begin{array}{l}\text { Cowlowied } \\
\text { Dovenneme }\end{array}$ & $\begin{array}{c}\text { Operaning } \\
\text { (jemin) }\end{array}$ & Anatiantêty \\
\hline & $a$ & & $e=a b$ & 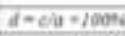 \\
\hline Pusien Ir & 270,10 & 29.13 & 257.07 & $00,17 \%$ \\
\hline Pexier IV & 293,17 & 94,50 & 118.57 & 60,594 \\
\hline Pevier V & 358.90 & 7,95 & 360.12 & $97,7 m$ \\
\hline Avider VI & 321,05 & 29,83 & 291.24 & 90,215 \\
\hline Powier Vat & 30,50 & 2,47 & 328,00 & 98,29 \\
\hline Aciev VIn & 292,4 & Y1.0에 & $228 \pi$ & 11,37 \\
\hline \multicolumn{4}{|l|}{ Rath-at: } & no,04t: \\
\hline
\end{tabular}
berikut :

Tabel. 3. Availability Mesin Packer Lama

Sumber: Pengolahan Data

Sedangkan nilai Availability pada masingmasing mesin packer baru serta rata-rata persentase Availability mesin packer baru

\begin{tabular}{|c|c|c|c|c|}
\hline \multirow[t]{2}{*}{ Mesin } & $\begin{array}{l}\text { Lodading Time } \\
\text { (Gain) }\end{array}$ & $\begin{array}{l}\text { Chyianmed } \\
\text { Dogranime } \\
\text { (jes) }\end{array}$ & $\begin{array}{l}\text { Orumativg Time } \\
\text { (jamy }\end{array}$ & Arailability \\
\hline & a & $b$ & $c=a-b$ & $d=d u=100 \%$, \\
\hline Packer IX & 352.37 & 15,32 & 337,05 & $95,65 \%$ \% \\
\hline Parcker X & 284,67 & 106,85 & 177,22 & 62.3990 \\
\hline \multicolumn{4}{|c|}{ Nability } & $79,02 \%$ \\
\hline
\end{tabular}
dapat dilihat pada tabel berikut :

Tabel 4. Availability Mesin Packer Baru
Sumber: Pengolahan Data

\subsubsection{Performance}

Perhitungan yang dilakukan untuk mendapatkan nilai Performance adalah dengan rumus :

Performance

$$
=\frac{\text { Actual Capacity Production }}{\text { Ideal Run Time }} \times 100 \%
$$

$A C P=\frac{\text { Total Produksi }}{\text { Operating Time }}$

Berdasarkan rumus diatas maka diperoleh nilai Performance pada masing-masing mesin packer lama serta rata-rata persentase

\begin{tabular}{|c|c|c|c|c|}
\hline Neris & $\begin{array}{l}\text { Total Rondulai } \\
\text { (nili) }\end{array}$ & $\begin{array}{l}\text { Arrual Copporty } \\
\text { Produrtion } \\
\text { (rak mentip }\end{array}$ & 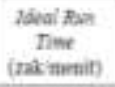 & Anofornance \\
\hline Aunke $\mathrm{Tl}$ & 474780 & 30,67410939 & 4023 & 76.259 \\
\hline Packer iv & 4E3)tes & 4li 95954134 & 46,23 & $101 \mathrm{~kg}$ \\
\hline Farke V & $82+482$ & 87100706 & 40,23 & 73,858 \\
\hline Purbe 17 & 33445 & 36 ESม & 40,23 & $76 \mathrm{~cm}$ \\
\hline Packe VII & 616220 & $31,7213426 ?$ & 4023 & 78.858 \\
\hline Parke VIII & 427670 & 31.57121554 & 4023 & 71.458 \\
\hline \multicolumn{4}{|c|}{ Rats cta Peformand } & 20,99\%: \\
\hline
\end{tabular}
Performance mesin packer lama pada tabel berikut :

Tabel 5. Perfomance Mesin Packer Lama

Sumber: Pengolahan Data

Sedangkan nilai Performance pada masing-masing mesin packer baru serta rata-

\begin{tabular}{|c|c|c|c|c|}
\hline Mesin & $\begin{array}{l}\text { Total Prodiasi } \\
\text { (mak) }\end{array}$ & $\begin{array}{l}\text { Actual Copacity } \\
\text { Prodsction } \\
\text { (zak menit) }\end{array}$ & $\begin{array}{l}\text { Aca' Ran } \\
\text { Tive } \\
\text { (nkmenit) }\end{array}$ & Pefornauce \\
\hline Pacher $\mathrm{LX}$ & 704120 & 34,81798173 & 40.23 & 86.554 \\
\hline Puncer X & 485670 & 45,9570026 & 60,23 & 114,245 \\
\hline \multicolumn{4}{|c|}{ RataratiaPeformance } & 100,404 \\
\hline
\end{tabular}
rata persentase Performance mesin packer baru dapat dilihat pada tabel berikut :

Tabel 6. Perfomance Mesin Packer Baru

Sumber: Pengolahan Data

\subsubsection{Quality}

Perhitungan yang dilakukan untuk mendapatkan nilai Quality adalah dengan rumus :

$$
\text { Quality }=\frac{\text { Output }- \text { Reject }}{\text { Output }} \times 100 \%
$$

Berdasarkan rumus diatas maka diperoleh nilai Quality pada masing-masing mesin 
packer lama serta rata-rata persentase Quality mesin packer lama pada tabel 7.

Sedangkan nilai Quality pada masingmasing mesin packer baru serta rata-rata persentase Quality mesin packer baru dapat dilihat pada tabel. 8 .

Tabel. 7 Quality Mesin Packer Lama

\begin{tabular}{|l|r|r|r|}
\hline \multicolumn{1}{|c|}{ Menin } & Output (rak) & Reject (zak) & \multicolumn{1}{|c|}{ Quality } \\
\hline Packer III & 474780 & 1142 & $99,76 \%$ \\
\hline Packer IV & 463765 & 765 & $99,84 \%$ \\
\hline Packer V & 624482 & 576 & $99,86 \%$ \\
\hline Pacher VI & 538656 & 1511 & $99,72 \%$ \\
\hline Packer VII & 616720 & 1003 & $99,84 \%$ \\
\hline Packer VII & 427670 & 770 & $99,82 \% 6$ \\
\hline \multicolumn{2}{|c|}{ Rata-rata Qualiry } & & $99,81 \%$ \\
\hline
\end{tabular}

Sumber: Pengolahan Data

Tabel. 8. Quality Mesin Packer Baru

\begin{tabular}{|c|r|r|r|}
\hline Mesin & Output (zak) & Reject (zak) & \multicolumn{1}{|c|}{ Quality } \\
\hline Packer IX & 704120 & 1699 & $99,76 \%$ \\
\hline Packer X & 458670 & 1682 & $99,66 \%$ \\
\hline \multicolumn{2}{|c|}{ Rata-rata Oualizy } & & 99,7156 \\
\hline
\end{tabular}

Sumber: Pengolahan Data

\subsubsection{Overall Equipment Effectiveness (OEE)}

Nilai OEE diperoleh dari perkalian ketiga rasio utama (Availability, Performance, dan Quality) seperti pada rumus berikut :

\section{OEE $=$ Availability $\times$ Performance $\times$ Quality}

Berdasarkan rumus diatas maka diperoleh nilai OEE pada masing-masing mesin packer lama serta rata-rata OEE mesin packer lama pada tabel berikut :

Tabel 9. OEE Mesin Packer Lama

\begin{tabular}{|c|c|c|c|c|}
\hline Mesin & dualahitinge & Peformonce 60 & Qualin 60 & OEE (S) \\
\hline Packer III & 90,17 & 76,25 & 99,76 & 6855 \\
\hline Packer IV & 66.55 & 101,89 & 99.54 & 67,69 \\
\hline Packer V & 97,77 & 73,85 & 99,56 & 72.10 \\
\hline Paxker VI & 90,71 & 76,62 & 99,72 & 6931 \\
\hline Packer VII & 93.35 & 78.85 & 99.14 & 73,40 \\
\hline Packer VIII & $\$ 1,37$ & $7 x, 45$ & 99,52 & 63,74 \\
\hline \multicolumn{4}{|c|}{ SataratuOEE ( 6 ) } & 69,14 \\
\hline
\end{tabular}

Sumber: Pengolahan Data

Sedangkan nilai OEE pada masingmasing mesin packer baru serta rata-rata $\mathrm{OEE}$ mesin packer baru dapat dilihat pada tabel berikut :

Tabel 10. OEE Mesin Packer Baru

\begin{tabular}{|c|c|c|c|c|}
\hline Mesin & Avaliabiling $(9 / 9)$ & Performance (\%) & Qualing (\%) & OEE \\
\hline Packer IX & 95,65 & 86.55 & 99,76 & 82.58 \\
\hline Packer X & 62.39 & 114,24 & 99,66 & 71,02 \\
\hline \multicolumn{4}{|l|}{ Ratatan } & 76,80 \\
\hline
\end{tabular}

Sumber: Pengolahan Data

\subsubsection{Perbandingan OEE}

Perbandingan nilai OEE dilakukan setelah mendapatkan nilai Availability, Performance, dan Quality dari hasil pengolahan data serta memperoleh nilai OEE dari mesin packer lama dan mesin packer baru. Adapun perbandingan tersebut dapat dilihat pada tabel berikut :

Tabel 11. Rekapitulasi Perbandingan

\begin{tabular}{|c|c|c|c|c|c|c|c|}
\hline \multicolumn{2}{|c|}{$\begin{array}{l}\text { RATA-RATA } \\
\text { ATARABIIII }\end{array}$} & \multicolumn{2}{|c|}{$\begin{array}{l}\text { RATARATA } \\
\text { PEPFORLAVCE }\end{array}$} & \multicolumn{2}{|c|}{$\begin{array}{c}\text { RAT4-RATA } \\
\text { QTAIIII }\end{array}$} & \multicolumn{2}{|c|}{$\begin{array}{l}\text { RATH-RATA } \\
\text { OEE }\end{array}$} \\
\hline $\begin{array}{l}\text { Prity } \\
\text { lane }\end{array}$ & $\begin{array}{l}\text { Paxe } \\
\text { Bru }\end{array}$ & $\begin{array}{l}\text { Paxe } \\
\text { Iant }\end{array}$ & $\begin{array}{l}\text { Pecter } \\
\text { Sern }\end{array}$ & $\begin{array}{l}\text { Puter } \\
\text { lent }\end{array}$ & $\begin{array}{l}\text { Paxy } \\
\text { Ben }\end{array}$ & $\begin{array}{l}\text { Paxb } \\
\text { Iane }\end{array}$ & $\begin{array}{l}\text { Paxe } \\
\text { Ben }\end{array}$ \\
\hline $86,64 \%$ & $79,02 \%$ & $80.99 \%$ & $100.40 \%$ & $99,81 \%$ & $99,71 \%$ & $69,14^{\circ}$ & $76.80 \%$ \\
\hline
\end{tabular}

Sumber: Pengolahan Data

\section{KESIMPULAN}

Dari hasil analisis yang telah dilakukan peneliti, maka peneliti dapat memberikan kesimpulan sebagai berikut:

1) Nilai OEE mesin packer baru lebih tinggi dari pada mesin packer lama. Hal ini berarti menunjukkan bahwa efektifitas mesin packer baru lebih tinggi dari pada mesin packer lama.

2) Nilai OEE yang diperoleh pada mesin packer lama dan mesin packer baru masih belum mencapai standar World Class OEE. Dimana untuk mencapai standar World Class OEE mesin packer harus mencapai skor sebesar $85,00 \%$.

\section{DAFTAR KEPUSTAKAAN}

Ernita, Tri, dkk. Buku Panduan Penulisan dan Ujian Skripsi STTIND Padang, Sekolah Tinggi Teknolgi Industri Padang, Padang, 2012.

Blanchard, B.S, Maintainability: A Key to Effective Serviceability \& Maintenance Management, John Willey \& Sonc Inc., NewYork, 1995.

Corder Anthony, Teknik Manajemen Pemeliharaan, Erlangga, Jakarta, 1996.

Dkk, Singarimbun, Metoda Penelitian Survey, LP3ES, Jakarta, 2003. 
Heizer Jay dan Barry Render, Prinsip-Prinsip Manajemen Operasi, Salemba Empat, Jakarta, 2001.

Nakajima, S, Introduction to Total Productive Maintenance, Productivity Press, Cambridge, 1988

Nazir Moh, Metode Penelitian, Ghalia Indonesia, Jakarta Selatan, 2009.

Pintelon, L.M. and Gelders, L.F. Maintenance Management Decision Making, European Journal of Operation Research 58, 1992.

Sujadi Prawirosentono, Manajemen Operasi Analisis dan Studi Kasus, Bumi Aksara, Jakarta, 2001.

Tampubolon Manahan, Manajemen Operasional, Ghalia Indonesia, Jakarta, 2004.

Wahjudi, Didik, dkk. Studi Kasus Peningkatan Overall Equipment Effectiveness (OEE) Melalui Implementasi Total Preventive Maintenance (TPM), Universitas Kristen Petra, Surabaya, 2009.

Rahman, Arif, dkk. Analisis Overall Equipment Effectiveness (OEE) Dalam Meminimalisi Six Big Losses Pada Mesin Produksi Dual Filters DD07, Universitas Brawijaya, Malang, 2013. 